\title{
BMJ Open Prognostic significance of occlusion length in recanalized chronic total occlusion lesion: a retrospective cohort study with 5-year follow-up
}

\author{
Tao Tian (D , , ${ }^{1}$ Changdong Guan, ${ }^{2}$ Lijian Gao, ${ }^{1}$ Lei Song, ${ }_{1}^{1}$ Jiansong Yuan, ${ }^{1}$ \\ Fenghuan Hu, ${ }^{1}$ Kefei Dou, ${ }^{1,3}$ Yida Tang, ${ }^{1,3}$ Yongjian Wu, ${ }^{1,3}$ Yuejin Yang, ${ }^{1,3}$ \\ Yinxiao Bai, ${ }^{4}$ Jingang Cui, ${ }^{1}$ Bo Xu, ${ }^{2,3}$ Shubin Qiao, ${ }^{1,3}$ Weixian Yang ${ }^{1,3}$
}

To cite: Tian T, Guan C, Gao L, et al. Prognostic significance of occlusion length in recanalized chronic total occlusion lesion: a retrospective cohort study with 5-year follow-up. BMJ Open 2020;10:e038302. doi:10.1136/ bmjopen-2020-038302

- Prepublication history and additional material for this paper are available online. To view these files, please visit the journal online (http://dx.doi org/10.1136/bmjopen-2020038302).

Received 10 March 2020 Revised 20 April 2020 Accepted 29 May 2020
Check for updates

(c) Author(s) (or their employer(s)) 2020. Re-use permitted under CC BY-NC. No commercial re-use. See rights and permissions. Published by BMJ.

For numbered affiliations see end of article.

Correspondence to Professor Weixian Yang; wxyang2009@sina.com and Professor Shubin Qiao; qsbfw@sina.com

\section{ABSTRACT}

Objectives This study sought to investigate the relationship between occlusion length and long-term outcomes of patients with recanalised chronic total occlusion (CTO) lesion.

Design A retrospective cohort study.

Setting Fuwai Hospital, National Center for Cardiovascular Disease, Beijing, China

Participants Consecutive patients with successfully recanalised CTO were included from January 2010 to December 2013.

Primary and secondary outcome measures The primary endpoint of the present study was a composite event of all-cause death and myocardial infarction (MI). The secondary endpoints included target lesion revascularisation (TLR) and target vessel revascularisation (TVR).

Results A total of 1987 patients were included and 1801 (90.6\%) subjects completed 5-year follow-up in this study. Based on occlusion length, the patients were divided equally into two groups: short (length $<15 \mathrm{~mm}, \mathrm{n}=957$ ) and long (length $\geq 15 \mathrm{~mm}, \mathrm{n}=1030$ ) CTO group. KaplanMeier survival curve showed no significant difference in the risk of the composite primary endpoint between short and long CTO groups $(p=0.242)$. Receiver operating characteristic curve analysis also established occlusion length $\geq 15 \mathrm{~mm}$ as a cut-off value for predicting TLR and TVR, with an area under the curve of 0.604 (95\% Cl: 0.569 to $0.638, \mathrm{p}<0.001$ ) and 0.605 ( $95 \% \mathrm{Cl}: 0.572$ to 0.638 ; $\mathrm{p}<0.001)$. Kaplan-Meier analysis revealed that the risks for TLR $(p=0.002)$ and TVR $(p=0.002)$ were higher in a patient with long CTO lesion. Multivariate Cox analysis also identified long CTO lesion as an independent predictor of TLR (HR: 1.539, 95\% Cl: 1.033 to 2.293; $p=0.034$ ) and TVR (HR: $1.476,95 \% \mathrm{Cl}: 1.012$ to $2.151 ; p=0.043$ ).

Conclusion Patients with long CTO lesion did not show a higher risk of death and MI after recanalisation, but had higher risks of TLR and TVR. Lesion with occlusion length $\geq 15 \mathrm{~mm}$ should be under close surveillance for restenosis after recanalisation.

\section{INTRODUCTION}

Percutaneous recanalisation of chronic total occlusion (CTO) contributes to relieving
Strengths and limitations of this study

- This was a long-term follow-up study with large sample size.

- A dedicated database was prospectively used to document the information about baseline demographics, laboratory examinations, stenting and so on.

- All angiographic and procedural characteristics were evaluated by an independent Core Laboratory and all adverse events were adjudicated by an independent committee.

- All patients in the present study were retrospectively included from 2010 to 2013.

- Chronic total occlusion intervention was at a preliminary stage in China in the first decade of the 21st century, so the results need to be confirmed by researches based on the current practice.

regional myocardial ischaemia and improving quality of life when clinically indicated. ${ }^{1}$ Previously, percutaneous coronary intervention (PCI) of CTO lesions was considered as the last barrier to full percutaneous revascularisation of patients. Reported success rates of CTO PCI were approximately $70 \%-80 \%$ in the first decade of the 21st century. ${ }^{2}$ However, with development of novel equipment and evolution of therapeutic strategy, the success rates have significantly improved in the past decade, with experienced centres around the world consistently achieving the rates of $85 \%-90 \%{ }^{3-6}$

Many factors can affect successful CTO PCI. Apart from operator's experience, it is largely influenced by the complexity of CTO lesion, including previous attempt, blunt stump, severe calcification, severe tortuosity, long segment occlusion, non-left anterior descending artery occlusion and so on, ${ }^{7-9}$ among which occlusion length is one of the 


\section{2,428 patients underwent PCI from 2010 to 2013}

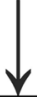

2,659 patients with 2,735 lesions received CTO PCI

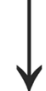

1,987 patients with 2060 CTO lesions were successfully recanalized

1801 patients with 1868 lesions completed 5-year follow-up

Figure 1 Patient flowchart of study enrollment and followup. CTO, chronic total occlusion; $\mathrm{PCl}$, percutaneous coronary intervention.

most important elements. ${ }^{78}$ It has already been well established that long CTO lesion is not only related to a lower success rate of recanalisation, but also a higher periprocedural complication rate. ${ }^{7810}$ But it remains unknown whether the length also has an impact on the long-term prognosis of the patients. As a result, we performed this study to investigate their relationship in a large Chinese cohort.

\section{METHODS}

\section{Patients}

From January 2010 to December 2013, consecutive patients undergoing CTO PCI were retrospectively included at Fuwai Hospital. Patients with a successfully recanalised CTO lesion were enrolled in the present study. A CTO lesion was defined as total occlusion of a coronary artery with thrombolysis in myocardial infarction (TIMI) grade 0 flow persisting for more than 3 months. ${ }^{11}$ The Multicenter CTO Registry of Japan (J-CTO) score was used to assess CTO lesion complexity. ${ }^{7}$ Synergy between Percutaneous Coronary Intervention with Taxus and Cardiac Surgery (SYNTAX) score was used to grade complexity of coronary artery disease. ${ }^{12}$

A dedicated database was used to prospectively document baseline demographics, laboratory examinations and stenting information. Angiographic and procedural characteristics were retrospectively evaluated by an independent Core Laboratory (Interventional Cardiovascular Imaging Core Laboratory, National Center for Cardiovascular Disease, Beijing, China). Clinical follow-up visits at 1 month, 6 months, 1 year and annually up to 5 years were carried out by an independent office. All adverse events were adjudicated and evaluated by an independent clinical events committee. All enrolled patients were willing to take part in this research and provided their informed consent documents.

\section{Procedures and antiplatelet regimens}

Coronary angioplasty and PCI were performed through femoral or/and radial artery according to standard methods. Antegrade wiring was most commonly used in the present population, while retrograde approach via collateral pathways was also performed and mainly by experienced operators. Crossing strategy, guide catheter selection and stent type, as well as intravascular imaging utilisation was left to the discretion of the operators. Procedural success was defined as reperfusion of the occluded vessel.

Patients were prescribed daily aspirin (100 mg once daily) and clopidogrel (75 mg once daily) for at least 6 days, or a loading dose (aspirin $300 \mathrm{mg}$, clopidogrel $300 \mathrm{mg}$ ) before the procedure. After PCI procedure, pharmacological treatments were at each operator's discretion, mainly patients were maintained on aspirin (100 mg once daily) indefinitely and clopidogrel $(75 \mathrm{mg}$ once daily) for at least 1 year.

\section{Endpoints and definitions}

The primary endpoint of the present study was a composite event of all-cause death and myocardial infarction (MI). The secondary endpoints included target lesion revascularisation (TLR) and target vessel revascularisation (TVR). The frequency of cardiac death, MI and stent thrombosis was also assessed. Cardiac death was defined as death of cardiac causes or any death without another known cause. MI was defined according to Society for Cardiovascular Angiography and Interventions definition. ${ }^{13}$ Stent thrombosis was defined as definite or probable based on Academic Research Consortium definitions according to the level of certainty. ${ }^{14}$ TLR and TVR were defined as clinically driven repeated revascularisation (either repeated PCI or coronary artery bypass grafting) of the initially treated target lesion and vessel, respectively.

\section{Patient and public involvement}

This study did not involve patients and the public in the design or planning of the study.

\section{Statistical analysis}

Data were expressed as mean $\pm \mathrm{SD}$ for continuous variables or as percentages for categorical variables. Differences in continuous variables were evaluated with the Student's t-test. The Wilcoxon rank-sum test was used when the distributions were unsymmetrical. The $\chi^{2}$ test was used for categorical analysis of nominal data. Fisher's exact test was used if the patient number in any group was less than five. A receiver operating characteristic (ROC) curve was used to determine the ability of occlusion length to predict outcomes. The Kaplan-Meier method was used to calculate the rate of survival free from the endpoint event. The log-rank test was used to compare survival curves among different patient groups. The Cox proportional hazards model was used to identify variables associated with the end point. Variables with $p$ values $\leq 0.10$ in the univariate analysis are included in the multivariate analysis. 
Statistical analyses were conducted with SAS V.9.4 (SAS Institute). All statistical tests were two-sided and $p$ values $<0.05$ were considered to be statistically significant.

\section{RESULTS}

\section{Baseline characteristics}

There were 2659 patients with 2735 lesions undergoing CTO PCI during the period mentioned above (figure 1). A total of 1987 patients (mean age: 57.1 10.5 ; female:
$17.3 \%$ ) with 2060 recanalised CTO lesions were included in present study. Forty-eight (2.3\%) lesion was previously attempted and retrograde approach was used in $37(1.8 \%)$ lesion. All the patients were divided equally into two CTO groups based on occlusion length: short group (occlusion length $<15 \mathrm{~mm}, \mathrm{n}=957$ ) and long group (occlusion length $\geq 15 \mathrm{~mm}, \mathrm{n}=1030$ ) (table 1). Patients in the short group were elder than those in the long one $(58.0 \pm 10.3$ vs $56.3 \pm 10.6$; $\mathrm{p}<0.001$ ), and women were found more in

Table 1 Clinical, angiographic and procedural characteristics

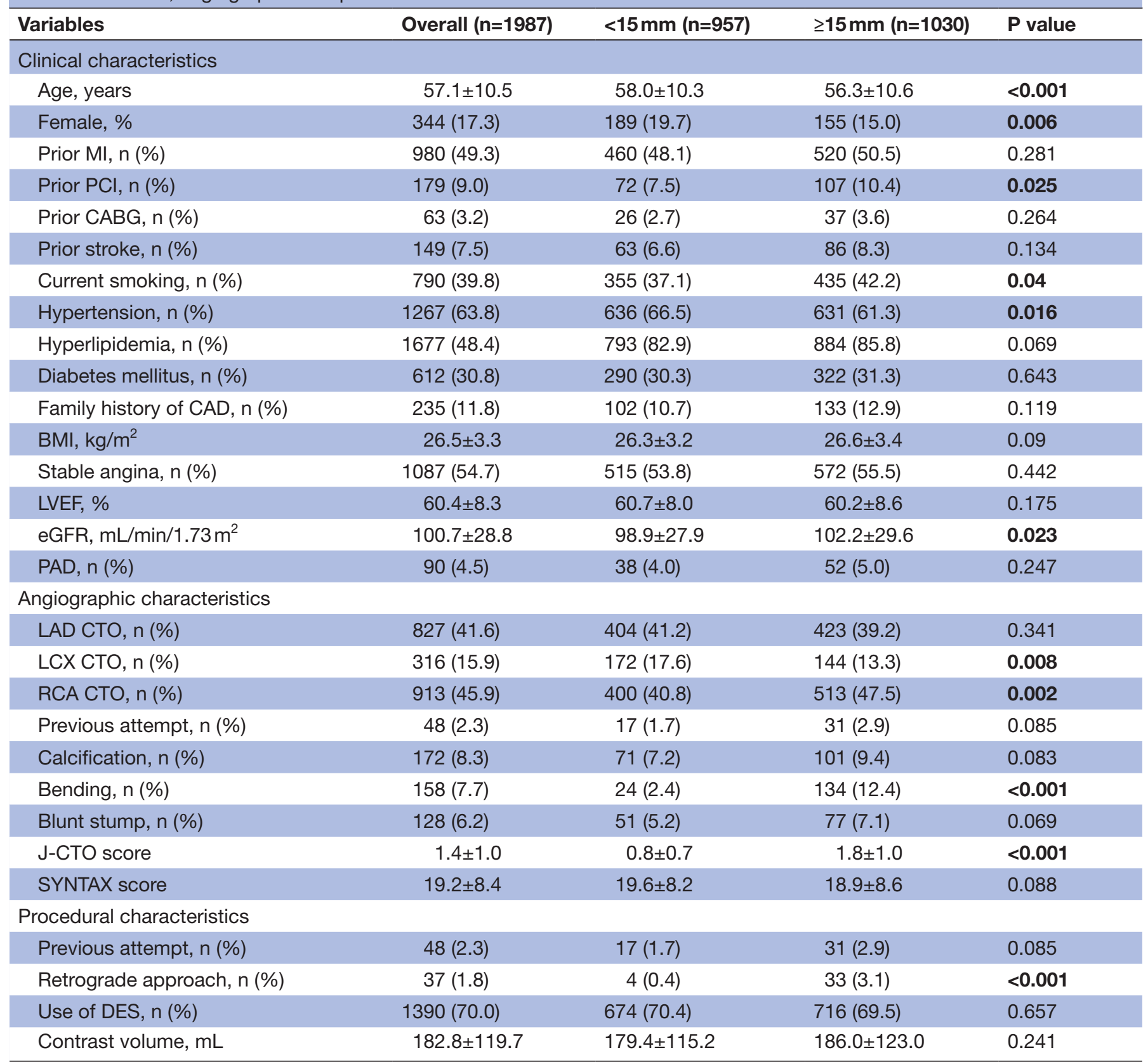

All values are shown as number $(\%)$ or mean \pm SD. Bold values are statistically significant $(p<0.05)$.

$\mathrm{BMI}$, body mass index; CABG, coronary artery bypass grafting; CAD, coronary artery disease; CTO, chronic total occlusion; DES, drug eluted stent; eGFR, estimated glomerular filtration rate; J-CTO, multicenter CTO registry of Japan; LAD, left anterior descending artery; LCX, left circumflex artery; LVEF, left ventricular ejection fraction; MI, myocardial infarction; PAD, peripheral artery disease; $\mathrm{PCI}$, percutaneous coronary intervention; RCA, right coronary artery; SYNTAX, synergy between percutaneous coronary intervention with taxus and cardiac surgery. 


\begin{tabular}{|c|c|c|c|c|}
\hline & $\begin{array}{l}\text { Overall } \\
(n=1801)\end{array}$ & $\begin{array}{l}<15 \mathrm{~mm} \\
(\mathrm{n}=878)\end{array}$ & $\begin{array}{l}\geq 15 \mathrm{~mm} \\
(\mathrm{n}=923)\end{array}$ & P value \\
\hline $\begin{array}{l}\text { All-cause death + } \\
\text { MI, } n(\%)\end{array}$ & $174(9.7)$ & $92(10.5)$ & $82(8.9)$ & 0.252 \\
\hline $\begin{array}{l}\text { All-cause death, } n \\
(\%)\end{array}$ & $97(5.4)$ & $50(5.7)$ & $47(5.1)$ & 0.56 \\
\hline $\begin{array}{l}\text { Cardiac death, } \\
\mathrm{n}(\%)\end{array}$ & $56(3.1)$ & $27(3.1)$ & $29(3.1)$ & 0.945 \\
\hline MI, n (\%) & $121(6.7)$ & 67 (7.6) & $54(5.9)$ & 0.131 \\
\hline $\begin{array}{l}\text { Target vessel } \\
\text { related, n (\%) }\end{array}$ & 105 (5.8) & 57 (6.5) & $48(5.2)$ & 0.242 \\
\hline $\begin{array}{l}\text { Definite/probable } \\
\text { stent thrombosis, } \\
\text { n (\%) }\end{array}$ & $58(3.2)$ & 29 (3.3) & $29(3.1)$ & 0.836 \\
\hline TLR, n (\%) & $136(7.6)$ & $48(5.5)$ & $88(9.5)$ & 0.001 \\
\hline TVR, n (\%) & $151(8.4)$ & 55 (6.3) & 96 (10.4) & 0.002 \\
\hline
\end{tabular}

All values are shown as number (\%). Bold values are statistically significant $(p<0.05)$.

MI, myocardial infarction; TLR, target lesion revascularisation; TVR, target vessel revascularisation.

the short group ( $19.7 \%$ vs $15.0 \%, \mathrm{p}=0.006)$. In addition, left circumflex artery CTOs were found more in the short group $(17.6 \%$ vs $13.3 \%, \mathrm{p}=0.008)$, while right coronary artery CTOs more in the other $(47.5 \%$ vs $40.8, \mathrm{p}=0.002)$.

\section{Clinical outcomes}

There were 1801 (90.6\%) patients completing 5-year follow-up (figure 1). Occurrence of the primary endpoint event was presented in table 2. Kaplan-Meier analysis showed that there was no significant difference in survival free from all-cause or MI between short and long CTO groups ( $\mathrm{p}=0.242$, figure 2 ).

Occurrence of the secondary endpoint events were listed in table 2. Coincidentally, ROC curve analysis also established occlusion length $\geq 15 \mathrm{~mm}$ as a cut-off value

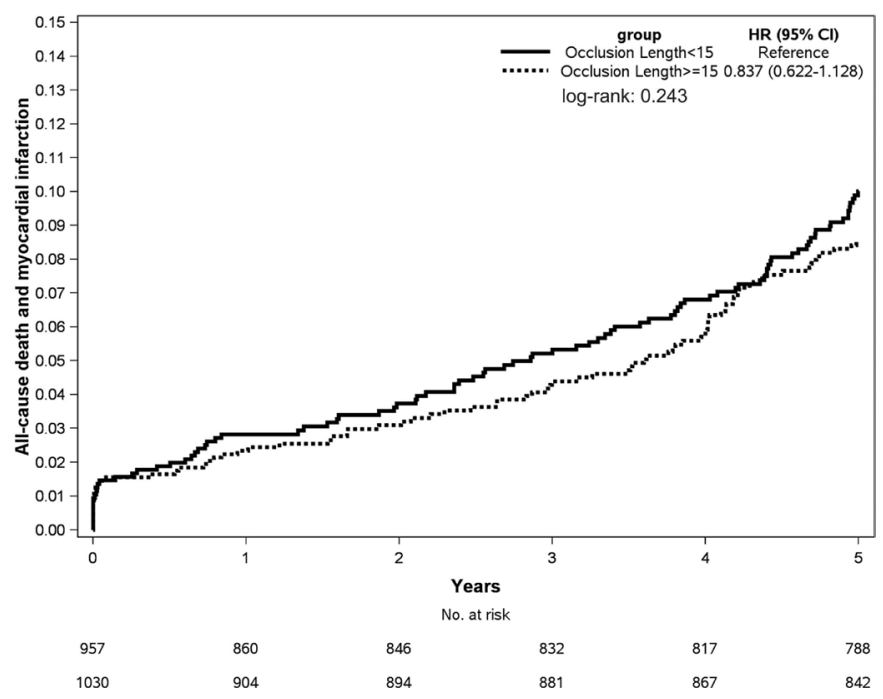

Figure 2 Survival free from all-cause death and myocardial infarction.
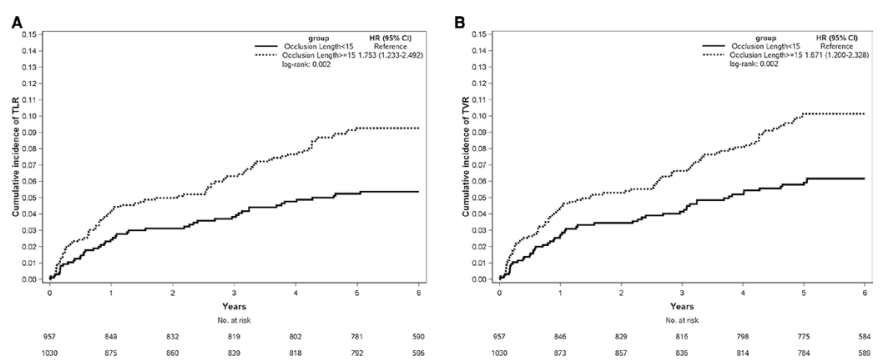

Figure 3 Survival free from TLR (A) and TVR (B). TLR, target lesion revascularisation; TVR, target vessel revascularisation.

for predicting both TLR and TVR, with an area under the curve of 0.604 (95\% CI: 0.569 to $0.638, \mathrm{p}<0.001)$ and 0.605 (95\% CI: 0.572 to 0.638 ; $\mathrm{p}<0.001$ ), respectively (online supplementary figure S1). Kaplan-Meier analysis showed that the patients with long CTO lesion had higher risks for TLR (HR: 1.753, 95\% CI: 1.233 to 2.492; $\mathrm{p}=0.002$ ) (figure 3A) and TVR (HR: 1.671, 95\% CI: 1.200 to 2.328; $\mathrm{p}=0.002$ ) (figure 3B). Multivariate Cox regression analysis also identified the length $\geq 15 \mathrm{~mm}$ as an independent predictor of TLR (HR: 1.539, 95\% CI: 1.033 to 2.293; $\mathrm{p}=0.034$ ) and TVR (HR: $1.476,95 \% \mathrm{CI}: 1.012$ to $2.151 ; \mathrm{p}=0.043)($ table 3$)$.

\section{DISCUSSION}

It is well established that occlusion length affects the success rate of CTO recanalisation, ${ }^{68}$ but its influence on the prognosis of the recanalised patients remains unclear. This 5-year follow-up study certified that occlusion length also had an impact on the long-term outcomes of these patients. The main findings of this study were as follows: (1) the long-term risk of death and MI was not significantly different between patients with successfully recanalised long and short CTO lesion; (2) patients with long CTO lesion had higher risks for TLR and TVR after the recanalisation and (3) occlusion length $\geq 15 \mathrm{~mm}$ might be a predictor for TLR and TVR.

In the present study, we found that the length of CTO lesion had no impact on combined 'hard' endpoint of death and MI. A CTO vessel is often collateralised by donor artery. After the recanalisation, antegrade flow of the CTO vessel restored and collateral function regressed. ${ }^{15}$ Initial study showed that collateral circulation had the potential to recover when recurrent occlusion developed in the recanalised lesion, ${ }^{16}$ and well-developed collateral was able to attenuate myocardial ischaemia and reduce allcause mortality. ${ }^{17}$ All these processes were independent from the length of CTO lesion, which could explain why the primary endpoint was comparable between patients with the short and long CTO.

Although the risk of 'hard' endpoint was not significantly different between long and short CTO patients, the long CTO lesion was associated with increased risks for 'soft' endpoints, including TLR and TVR, after recanalisation. The increased revascularisation could be explained by the following reasons. First of all, long CTO 


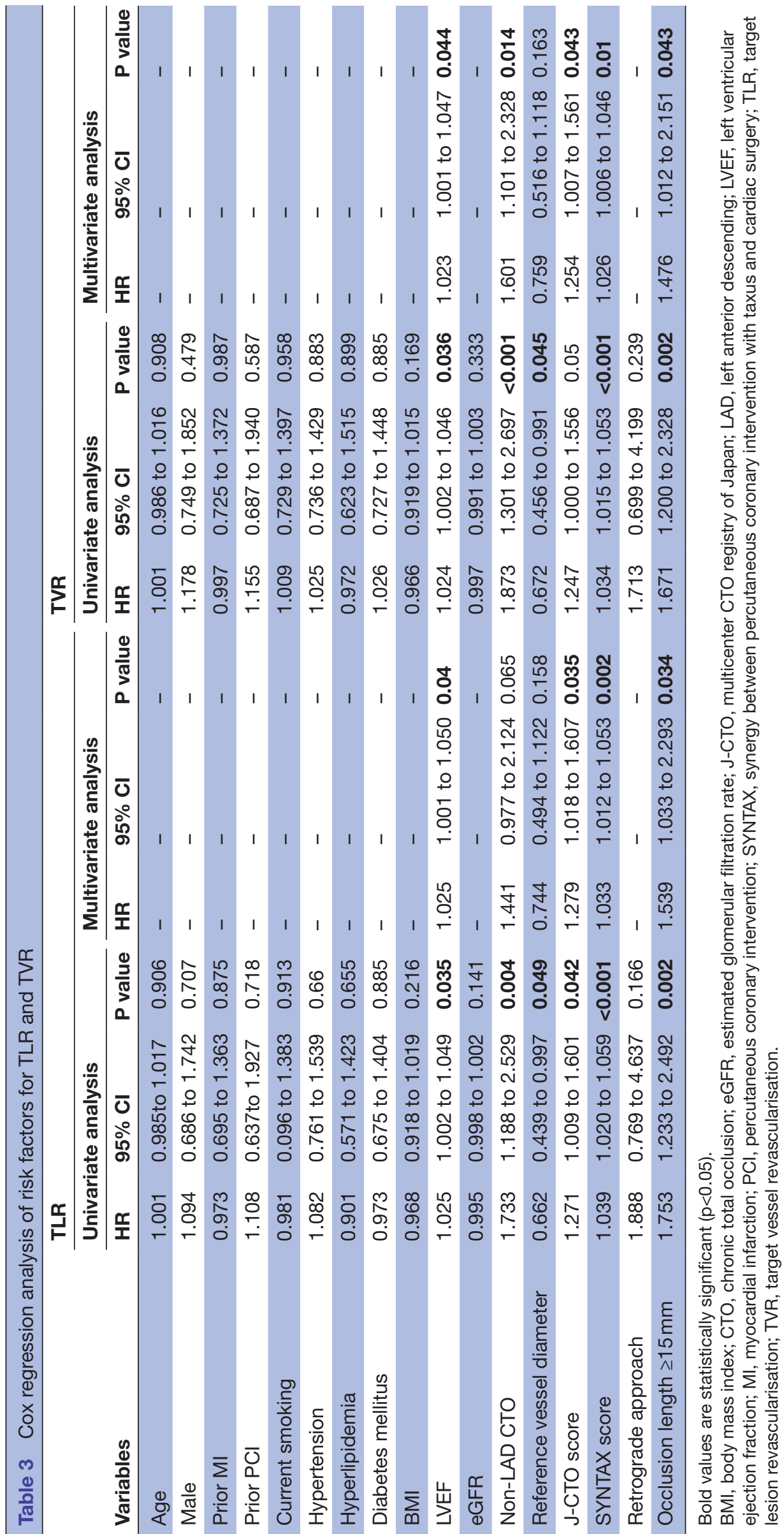


lesion always needs long stent implantation, which was closely bound up with occurrence of revascularisation in unselected patients undergoing drug-eluting stent implantation. ${ }^{18-20}$ For another, as our study showed, blunt stump, calcification and bending occurred more often in long CTO lesion, which signified that CTO lesions got more complex with increased occlusion length. Subintimal tracking and vessel injury seemed to be developed inevitably when management of complex CTO lesion. ${ }^{21-24}$ Some studies showed that extensive subintimal stenting and target vessel injury increased the chance of revascularisation. ${ }^{24} 25$

Recent studies evaluated the role of occlusion length on the outcomes of successful CTO PCI, ${ }^{26} 27$ however, there are still some questions needed to be answered. In the first place, the relationship between occlusion length and revascularisation requires to be analysed further. A 2-year follow-up study from Korea, which included 235 patients undergoing successful CTO PCI, showed that TVR occurred more often in patients with long CTO lesion, whereas TLR did not. In the present study, we demonstrated that occlusion length was associated with a higher rate of not only TVR, but also TLR. Small sample size and short follow-up period of Korean study might explain the inconsistent results. In addition, the occlusion length predicting TLR and TVR remains unknown. The present study constructed ROC curves to identify the best cut-off value for occlusion length to predict the two events, and found that the threshold value was $15 \mathrm{~mm}$ with acceptable sensitivity and specificity. This suggested that those with CTO length $\geq 15 \mathrm{~mm}$ might be under close surveillance for restenosis after recanalisation.

This study also had several limitations. First, the research was retrospective, so its results need to be confirmed by prospective studies. Second, CTO PCI was at a preliminary stage in China from 2010 to 2013, and recanalisation was first attempted and antegrade approach was used in most patients in the present study, so its results need to be confirmed by studies based on current CTO practice. Third, because of medical cost, intravascular ultrasound was only used in a small proportion of patients, so CTO length was measured by the core laboratory using angiography. Finally, the patients were not given regular angiographic follow-up; therefore, some adverse events, such as TLR and TVR, might not be recorded accurately.

\section{CONCLUSIONS}

Occlusion length had an impact on the prognosis of recanalised CTO lesion. The long lesion was associated with a higher risk for TLR and TVR, but not death and MI. A lesion with occlusion length $\geq 15 \mathrm{~mm}$ should be under close supervised for restenosis after recanalisation.

\footnotetext{
Author affiliations

${ }^{1}$ Department of Cardiology, Fuwai Hospital, National Center for Cardiovascular Diseases, Chinese Academy of Medical Sciences, Beijing, China

${ }^{2}$ Catheterization Laboratories, Fuwai Hospital, National Center for Cardiovascular Diseases, Chinese Academy of Medical Sciences, Beijing, China
}

${ }^{3}$ National Clinical Research Center of Cardiovascular Diseases, Beijing, China ${ }^{4}$ Medical Research and Biometrics Center, Fuwai Hospital, National Center of Cardiovascular Disease, Chinese Academy of Medical Sciences, Bejing, China

Acknowledgements The authors thank staffs in the Department of Cardiology and Catheterization Laboratory, Fuwai Hospital, for their research contributions.

Contributors TT contributed to the concept and wrote the manuscript; $C G$ and $Y B$ participated in data collection and statistical analysis; LG, LS, JY, FH, KD, YT, YW, YY and JC were responsible for including patients; $B X, S-B Q$ and WY participated in study design and manuscript revision. All authors checked the final version of the manuscript.

Funding This study was supported by the Fundamental Research Funds for the Central Universities of China (No 3332018058) and the Postgraduate Education and Teaching Reform Project of Peking Union Medical College (No 10023201900203).

\section{Competing interests None declared.}

Patient and public involvement Patients and/or the public were not involved in the design, or conduct, or reporting, or dissemination plans of this research.

Patient consent for publication Not required.

Ethics approval This study followed the guidelines of the Declaration of Helsinki and was approved by the Ethics Committee of Fuwai Hospital.

Provenance and peer review Not commissioned; externally peer reviewed.

Data availability statement Data are available upon reasonable request.

Open access This is an open access article distributed in accordance with the Creative Commons Attribution Non Commercial (CC BY-NC 4.0) license, which permits others to distribute, remix, adapt, build upon this work non-commercially, and license their derivative works on different terms, provided the original work is properly cited, appropriate credit is given, any changes made indicated, and the use is non-commercial. See: http://creativecommons.org/licenses/by-nc/4.0/.

\section{ORCID iD}

Tao Tian http://orcid.org/0000-0003-0014-6221

\section{REFERENCES}

1 Brilakis ES, Mashayekhi K, Tsuchikane E, et al. Guiding principles for chronic total occlusion percutaneous coronary intervention. Circulation 2019;140:420-33.

2 Patel VG, Brayton KM, Tamayo A, et al. Angiographic success and procedural complications in patients undergoing percutaneous coronary chronic total occlusion interventions: a weighted metaanalysis of 18,061 patients from 65 studies. JACC Cardiovasc Interv 2013;6:128-36.

3 Suzuki Y, Tsuchikane E, Katoh O, et al. Outcomes of percutaneous coronary interventions for chronic total occlusion performed by highly experienced japanese specialists: the first report from the Japanese CTO-PCI expert registry. JACC Cardiovasc Interv 2017;10:2144-54.

4 Sapontis J, Salisbury AC, Yeh RW, et al. Early procedural and health status outcomes after chronic total occlusion angioplasty: a report rrom the OPEN-CTO registry (outcomes, patient health status, and efficiency in chronic total occlusion hybrid procedures). JACC Cardiovasc Interv 2017;10:1523-34.

5 Tajti P, Karmpaliotis D, Alaswad K, et al. The hybrid approach to chronic total occlusion percutaneous coronary intervention: update from the PROGRESS CTO registry. JACC Cardiovasc Interv 2018;11:1325-35.

6 Konstantinidis NV, Werner GS, Deftereos S, et al. Temporal trends in chronic total occlusion interventions in Europe. Circ Cardiovasc Interv 2018;11:e006229.

7 Morino Y, Abe M, Morimoto T, et al. Predicting successful guidewire crossing through chronic total occlusion of native coronary lesions within 30 minutes: the J-CTO (multicenter CTO registry in Japan) score as a difficulty grading and time assessment tool. JACC Cardiovasc Interv 2011;4:213-21.

8 Alessandrino G, Chevalier B, Lefèvre T, et al. A clinical and angiographic scoring system to predict the probability of successful first-attempt percutaneous coronary intervention in patients with total chronic coronary occlusion. JACC Cardiovasc Interv 2015;8:1540-8.

9 Christopoulos G, Kandzari DE, Yeh RW, et al. Development and validation of a novel scoring system for predicting technical success of chronic total occlusion percutaneous coronary interventions: 
the progress CTO (prospective global Registry for the study of chronic total occlusion intervention) score. JACC Cardiovasc Interv 2016;9:1-9.

10 Danek BA, Karatasakis A, Karmpaliotis D, et al. Development and validation of a scoring system for predicting periprocedural complications during percutaneous coronary interventions of chronic total occlusions: the prospective global registry for the study of chronic total occlusion intervention (progress CTO) complications score. J Am Heart Assoc 2016;5.

11 Stone GW, Kandzari DE, Mehran R, et al. Percutaneous recanalization of chronically occluded coronary arteries: a consensus document: part I. Circulation 2005;112:2364-72.

12 Sianos G, Morel M-A, Kappetein AP, et al. The SYNTAX score: an angiographic tool grading the complexity of coronary artery disease. Eurolntervention 2005;1:219-27.

13 Moussa ID, Klein LW, Shah B, et al. Consideration of a new definition of clinically relevant myocardial infarction after coronary revascularization: an expert consensus document from the society for cardiovascular angiography and interventions (Scal). J Am Coll Cardiol 2013;62:1563-70.

14 Cutlip DE, Windecker S, Mehran R, et al. Clinical end points in coronary stent trials: a case for standardized definitions. Circulation 2007:115:2344-51.

15 Zimarino M, Ausiello A, Contegiacomo G, et al. Rapid decline of collateral circulation increases susceptibility to myocardial ischemia: the trade-off of successful percutaneous recanalization of chronic total occlusions. J Am Coll Cardiol 2006;48:59-65.

16 Werner GS, Emig U, Mutschke O, et al. Regression of collateral function after recanalization of chronic total coronary occlusions: a serial assessment by intracoronary pressure and doppler recordings. Circulation 2003:108:2877-82.

17 Seiler C. Assessment and impact of the human coronary collateral circulation on myocardial ischemia and outcome. Circ Cardiovasc Interv 2013;6:719-28.

18 Yeh RW, Normand S-LT, Wolf RE, et al. Predicting the restenosis benefit of drug-eluting versus bare metal stents in percutaneous coronary intervention. Circulation 2011;124:1557-64.
19 Stolker JM, Kennedy KF, Lindsey JB, et al. Predicting restenosis of drug-eluting stents placed in real-world clinical practice: derivation and validation of a risk model from the event registry. Circ Cardiovasc Interv 2010;3:327-34.

20 Kong MG, Han J-K, Kang J-H, et al. Clinical outcomes of long stent in the drug-eluting stent era: patient-level pooled analysis from the GRAND-DES registry. Eurolntervention 2019:EIJ-D-19-00296.

21 Finn MT, Doshi D, Cleman J, et al. Intravascular ultrasound analysis of intraplaque versus subintimal tracking in percutaneous intervention for coronary chronic total occlusions: one year outcomes. Catheter Cardiovasc Interv 2019;93:1048-56.

22 Azzalini L, Poletti E, Ayoub M, et al. Coronary artery perforation during chronic total occlusion percutaneous coronary intervention: epidemiology, mechanisms, management, and outcomes. Eurolntervention 2019;15:e804-11.

23 Danek BA, Karatasakis A, Tajti P, et al. Incidence, treatment, and outcomes of coronary perforation during chronic total occlusion percutaneous coronary intervention. Am J Cardiol 2017;120:1285-92.

24 Song L, Maehara A, Finn MT, et al. Intravascular ultrasound analysis of intraplaque versus subintimal tracking in percutaneous intervention for coronary chronic total occlusions and association with procedural outcomes. JACC Cardiovasc Interv 2017; 10:1011-21.

25 Karatasakis A, Danek BA, Karacsonyi J, et al. Mid-term outcomes of chronic total occlusion percutaneous coronary intervention with subadventitial vs. intraplaque crossing: a systematic review and meta-analysis. Int J Cardiol 2018;253:29-34.

26 Ahn J, Rha S-W, Choi B, et al. Impact of chronic total occlusion lesion length on six-month angiographic and 2-year clinical outcomes. PLoS One 2018;13:e0198571.

27 Kim G-S, Kim B-K, Shin D-H, et al. Predictors of poor clinical outcomes after successful chronic total occlusion intervention with drug-eluting stents. Coron Artery Dis 2017;28:381-6. 